\title{
Electronic Equipment Loads Telemetry in Ferry Ship Passenger Room Based on Long Range Wireless Communication (LoRA)
}

\author{
Aldian Dwi Pamungkas ${ }^{1}$ *, Lilik Subiyanto, Afif Zuhri Arfianto ${ }^{1}$, Hendra Agus Widodo ${ }^{1}$, \\ Rachmad Andri Atmoko ${ }^{2}$ \\ ${ }^{1}$ Department of Marine Electrical Engineering, Politeknik Perkapalan Negeri Surabaya (PPNS), Indonesia \\ ${ }^{2}$ Mokosoft Technology, Research and Development Division, Indonesia
}

Article history:

Submission January 2020

Revised May 2020

Accepted May 2020

${ }^{*}$ Corresponding author:

E-mail: aldian@aedmae.org

\begin{abstract}
The development of information technology both software and hardware support development in various fields, especially in the field of electronics. This progress can be used in making automation systems and controlling electronic and electrical components. With the increasing need for system monitoring in real-time, a model that is more than just portable storage can be developed, using telemetry (remote measurement) systems. This research makes a prototype that is used for remote monitoring of electronic equipment telemetry in the passenger space of ferries using wireless communications. Radiofrequency is used for electronic equipment located in the passenger space. The system is made using ACS 712 current sensor and ZMPT 101B voltage sensor to measure current and voltage monitored by long-range wireless communications (LoRa) to maintain the strength of the amplifier signal and the distance that the LoRa can reach. By utilizing the frequency of the LoRa, it is expected to monitor the load current and voltage generated by electronic equipment in the ferry passenger's passenger space. From the monitoring tool obtained the test results of testing Television with power 27 W and Voltage 19 Volt obtained the percentage of voltage error is $1.09 \%$ and the percentage of current error is $1.15 \% .3$. Based on the results of the test data, it can be concluded that the current, voltage in the passenger room of the JokoTole KMP ship is fluctuating. This needs to be done monitoring the current load on the ship, especially in the safety alarm system, electronic devices, pumps for the safety of shipping, which at KMP Joko Tole still uses conventional technology and the absence of adequate electrical system data support
\end{abstract}

Keywords: Telemetry, ACS 712 current sensor, ZMPT 101B voltage sensor

\section{Introduction}

From the monitoring tool obtained the test results of testing Television with power $27 \mathrm{~W}$ and Voltage 19 Volt obtained the percentage of voltage error is $1.09 \%$ and the percentage of current error is $1.15 \% .3$. Based on the results of the test data, it can be concluded that the current, voltage in the passenger room of the JokoTole KMP ship is fluctuating. This needs to be done monitoring the current load on the ship, especially in the safety alarm system, electronic devices, pumps for the safety of shipping, which at KMP Joko Tole still uses conventional technology and the absence of adequate electrical system data support.

This progress can be utilized in making automation and control systems for electronic and electrical components, especially monitoring the load current and voltage in the passenger room to be able to control the outgoing

\section{How to cite:}

Pamungkas AD, Subiyanto L, Arfianto AZ, Widodo HA, Atmoko RA (2020). Electronic equipment loads telemetry in ferry ship passenger room based on long range wireless communications (LoRA) . Indonesian Journal of Engineering Research 1 (1): 1 - 6. doi: 10.11594/ijer.01.01.01 
power. The measurement process is a fundamental process carried out in the development stage of electronic equipment. The results of the measurement process can be used to find out the characteristics of the electronic equipment being developed [1].

Measuring instruments available on the market are standard measuring devices that are often used in general conditions, such as thermometers used to measure the temperature of objects or rooms that are portable. Avometer used to measure voltage, current, and electrical resistance whose form is also portable and becomes a standard material for measuring electrical quantities. In this case, the available measuring devices can only be used in relatively general circumstances, even though in the market they are developed by utilizing digital technology. With the increasing need to monitor the system in real-time, a model that is more than just portable can be developed anywhere, by using a telemetry system (remote measurement)[2][3].

This monitoring model is carried out by utilizing radio waves as a medium for sending data, the advantage compared to portable systems is that this system can be used in real-time and does not need to carry out the measurement process near the object to be measured. Progress in the field of technology and science, especially in the field of control techniques (monitoring techniques), has been overgrowing [4][5].

This development facilitates communication and control of electronic devices, especially electronic equipment in ferry passenger rooms. Along with its development, a control system for monitoring remote load currents using Long Range Wireless Communications (LoRa) has been developed, so there is no need to use conventional methods [6][7]. Full remote load flow monitoring is urgently needed on the ferry passenger room electronic equipment. This is intended for monitoring load and voltage currents in the passenger compartment.

\section{Material and Methods}

This research method will explain the general description of research methods to be carried out in completing research. The method contains the work steps that can be seen in Figure 1.

\section{System Design Concept}

In designing the work system of LoRabased Load Flow Monitoring and telemetry voltage to be made. The work system to be implemented can be seen in Figure 2. In the Block diagram of the LORA-based telemetry load and voltage system, it can be seen that the data transmitter used is an electronic device that is in the passenger room of the ferry.
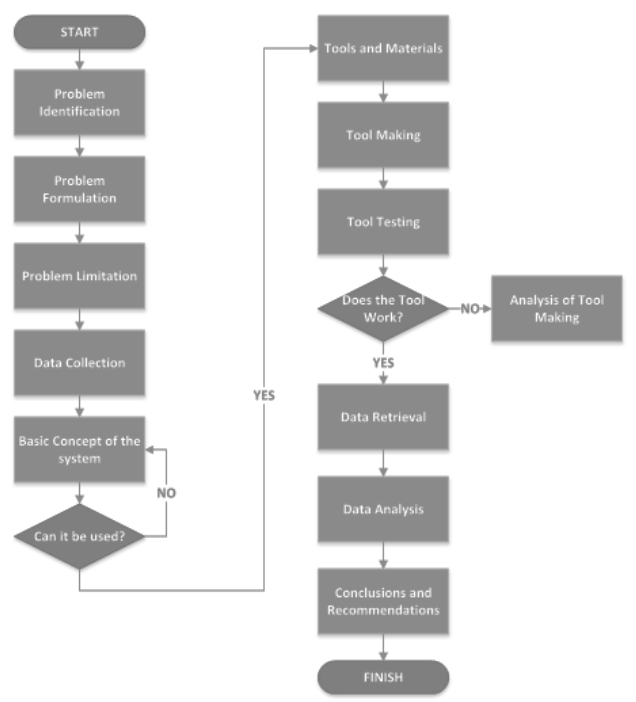

Figure 1. Research Flow 


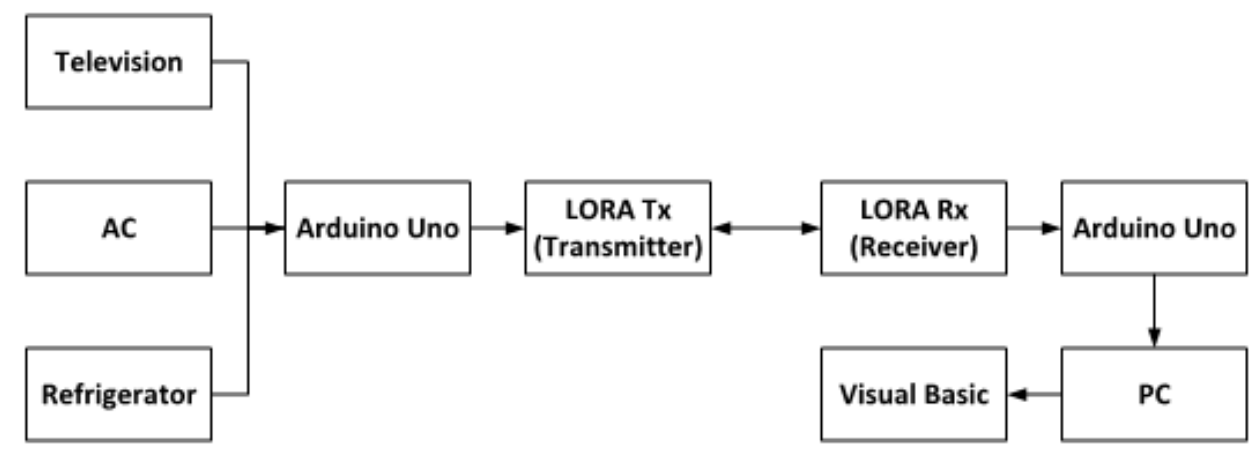

Figure 2. Block Diagram, LoRa-based Telemetry Load, and Voltage Systems

The electronic devices are television, refrigerator, and air conditioner. Then measurements are made using a Current Sensor and a voltage sensor to determine the results of current and voltage measurements. Then the data generated from the measurement of the current sensor and the voltage sensor are adjusted and processed by Arduino, which has been programmed, and the data received will be modulated using radio waves, which will be transmitted by LoRa. Then the transmitted data is received by the LoRa recipient [8][9][10]. The data is adjusted and processed by Arduino, which has been programmed to be displayed by the LCD on display to find out the measurement results as well passed to visual basic.

\section{Tool Making}

In making hardware based on the Telemetry Load Flow system specifications in the Long Range Wireless Communications Ferry Passenger Room, a current and voltage sensor test is carried out on the telemetry load current monitoring device. Load testing is carried out on the ferry passenger room. The tool that will be made as to the design in Figure 3.

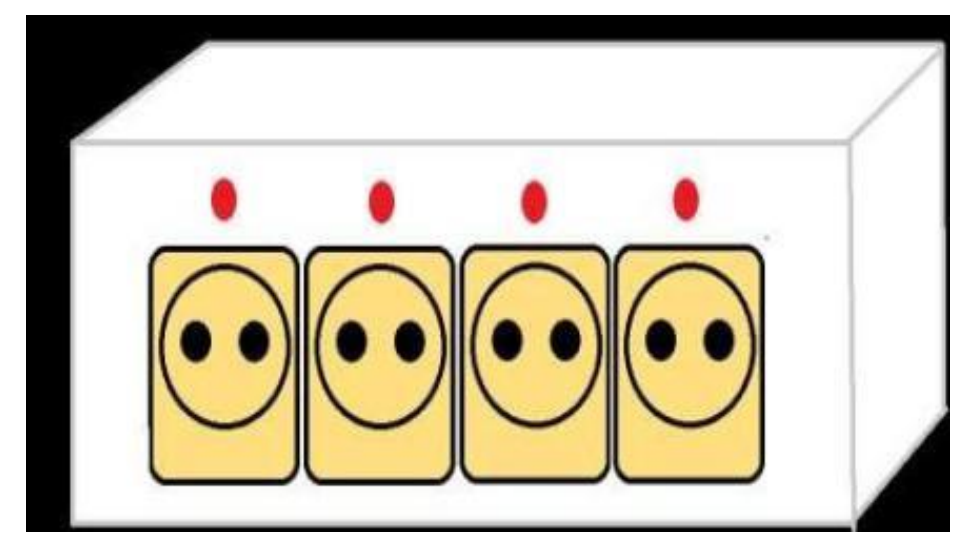

Figure 3. The Design of a Load Telemetry Monitoring Tool

Figure 3 is the design of a planned load telemetry monitoring tool. The image appears on the front of the planned tool with a length of 31 $\mathrm{cm}$, width $19 \mathrm{~cm}$, and a height of $10 \mathrm{~cm}[11]$.

\section{Tool Testing}

Tool testing is to find out the working ability of the tool made, whether it is following the design or not. Then the current and voltage 
tests in the passenger room of the ferry. Testing the load on the passenger room includes air conditioning, television, and refrigerator located in the passenger room of the ferry. Testing is done by comparing the manual testing of current and voltage using an Avometer to determine the performance of the load telemetry monitoring tool.

\section{Working System Tool and Wiring Diagrams}

If a failure is found in the testing process, an analysis of failures and problems will occur. Then a solution is found to fix the problem so that the tool can function optimally. Following is the wiring diagram of the load current telemetry monitoring tool in Figure 4.

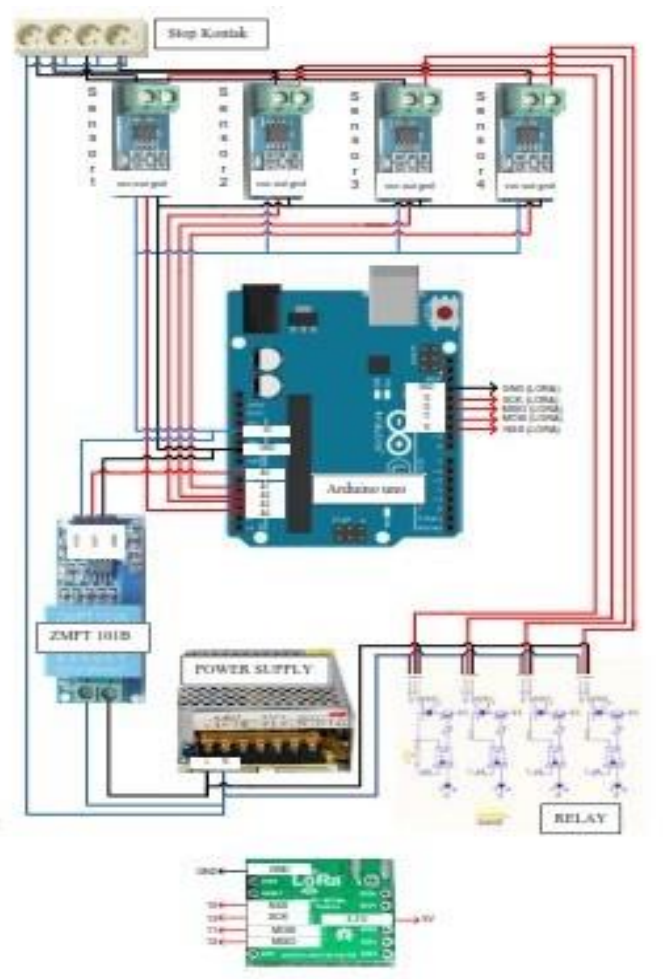

Figure 4. Wiring Diagram

Figure 4 showed that the load current telemetry monitoring tool wiring has four current sensors and a voltage sensor to read the output in the form of the measured current and voltage. Input voltage sensor on Arduino A0 port, Current sensor 1 in on Arduino A04 port, Current sensor 2 in on Arduino A3 port, Current sensor 3 in on Arduino A2 port, Current sensor 4 in on Arduino A1 port, LORA Module in Rx port and the Tx port on the web client and then on the webserver as the recipient of the incoming module data on the Arduino Rx and Tx ports which are then forwarded to the monitor to display the readings of the data by visual basic where the Arduino pins from A1 to A5 are connected to one $\mathrm{ADC}$ in resolution $10 \mathrm{bit}$.

\section{Results and Discussion}

This stage discusses the design of a telemetry load flow monitoring tool and the manufacture of equipment to the load testing that will be carried out in the passenger room and the VIP KMP Joko Tole passenger room. So in the future, it can be analyzed about the work of tools and the suitability of electronic equipment load (Television with power $27 \mathrm{~W}$ and Voltage 19 Volt ) current telemetry monitoring tools with the design of tools that have been done with the results of field testing conducted on the Joko Tole KMP ferry. So that the problems that exist on the ship regarding load currents and fluctuating voltages can be monitored to determine solutions to overcome these problems.

\section{Results and Testing of Voltage Sensors}

At this stage is an explanation of the design of a load current telemetry monitoring device to the voltage sensor used is the zmpt101b AC voltage sensor where the zmpt101b AC voltage sensor is a module used to measure 1 Phase AC Voltage. The zmpt101b voltage sensor is designed using a transformer so that it can only be used to read AC voltage, and then the voltage will be converted discrete into an analog to digital converter on pin A0 with a resolution of 10 bits. zmpt101b sensor has proper specifications in reading the data received.

From Figure 2.4 wiring of a voltage telemetry monitoring circuit, it can be seen that the input voltage sensor is on the Arduino A4 port and then processed to ADC4. With a binary number of 10 bits and able to read a maximum voltage of $247.5 \mathrm{~V}$ according to the program that has been done. Furthermore, each pin has a converter that is analog to digital, where the converter can change the signal received by the analog pin in the form of voltage and then converted into numbers so that it is easy to read. 


\section{Results and Testing of Current Sensors}

This stage is an explanation of the design of a load current telemetry monitoring tool to the current sensor used is the ACS 712 current sensor.

Table 1. Voltage Sensor Testing

\begin{tabular}{|c|c|c|c|}
\hline V Measure & V Test & $\begin{array}{l}\text { V Test Con- } \\
\text { version }\end{array}$ & Error \\
\hline $30 \mathrm{~V}$ & $31.15 \mathrm{~V}$ & 128.6 & $3.83 \%$ \\
\hline $40 \mathrm{~V}$ & $39.57 \mathrm{~V}$ & 163 & $1.07 \%$ \\
\hline $50 \mathrm{~V}$ & $48.48 \mathrm{~V}$ & 200.2 & $3.04 \%$ \\
\hline $60 \mathrm{~V}$ & $58.39 \mathrm{~V}$ & 241.1 & $2.68 \%$ \\
\hline $70 \mathrm{~V}$ & $68.04 \mathrm{~V}$ & 281 & $2.8 \%$ \\
\hline $80 \mathrm{~V}$ & $78.69 \mathrm{~V}$ & 324.9 & $1.63 \%$ \\
\hline $90 \mathrm{~V}$ & $89.09 \mathrm{~V}$ & 367.9 & $1.01 \%$ \\
\hline $100 \mathrm{~V}$ & $98.75 \mathrm{~V}$ & 407.8 & $1.25 \%$ \\
\hline $110 \mathrm{~V}$ & $109.15 \mathrm{~V}$ & 450.7 & $0.77 \%$ \\
\hline $120 \mathrm{~V}$ & $120.04 \mathrm{~V}$ & 495.7 & $0.03 \%$ \\
\hline $130 \mathrm{~V}$ & $129.7 \mathrm{~V}$ & 535.6 & $0.23 \%$ \\
\hline $140 \mathrm{~V}$ & $140.84 \mathrm{~V}$ & 581.6 & $0.6 \%$ \\
\hline $150 \mathrm{~V}$ & $150.99 \mathrm{~V}$ & 623.5 & $0.66 \%$ \\
\hline $160 \mathrm{~V}$ & $160.89 \mathrm{~V}$ & 664.4 & $0.55 \%$ \\
\hline $170 \mathrm{~V}$ & $170.8 \mathrm{~V}$ & 705.4 & $0.47 \%$ \\
\hline $180 \mathrm{~V}$ & $180.45 \mathrm{~V}$ & 745.2 & $0.25 \%$ \\
\hline $190 \mathrm{~V}$ & $190.85 \mathrm{~V}$ & 788.2 & $0.44 \%$ \\
\hline $200 \mathrm{~V}$ & $200.01 \mathrm{~V}$ & 826 & $0.005 \%$ \\
\hline $210 \mathrm{~V}$ & $210.41 \mathrm{~V}$ & 868.9 & $0.19 \%$ \\
\hline $220 \mathrm{~V}$ & $220.57 \mathrm{~V}$ & 910.95 & $0.25 \%$ \\
\hline
\end{tabular}

This current sensor function is to measure the current flowing at the load where the ACS 712 current sensor is a module used to measure 1 Phase AC. ACS 712 voltage sensor using the transfer function is the correlation between the physical value measured by the sensor and the ADC (Analog to Digital Converter) value then the discrete voltage will be converted into an analog to digital converter on pin A1A4 using a series circuit that uses four ACS 712 current sensors.

With a resolution of 10 bits, the ACS 712 current sensor has excellent specifications in reading the data received, but the reading results in alternating current tends to fluctuate. In Wiring current, the load current telemetry monitoring tool can be seen addressing the Arduino pin current sensor 1 in. On the Arduino A4 port, current sensor 2 in on the Arduino A3 port, current sensor 3 in on the Arduino A2 port, current sensor 4 in on the Arduino A1 port. As well as the AC voltage sensor, the ACS 712 Current Sensor is also connected to the Arduino Uno analog pin.

The process is also converted to analog to digital (ADC) with a range of 0 volts represented as data 0 and volts are represented as data 1023 ACS712 current sensor has a voltage sensitivity of $66-185 \mathrm{mV} / \mathrm{A}$. From the ACS712 current sensor datasheet specifications can measure from current (-) to current (+) Current sensor with a sensitivity of $185 \mathrm{mV} / \mathrm{A}$ can read measurements from -5 to +5 , Current sensor ACS712 20A with a sensitivity of $100 \mathrm{mV} / \mathrm{A}$ with measurements from -20 up to +20 . To produce data $0 \mathrm{~A}$ (Zero), the read voltage is reduced by 2.5 Volts or half the supply voltage (VCC) to get a value of A0 because the ACS712 current sensor uses a readable voltage then it must be divided by the sensitivity value according to the specifications of the sensor used. So it is formulated then, Flow Measurement Results. From the current sensor program one above, the current sensor 1 enters the A4 pin Arduino addressing, and it can be seen that the 4.95 value is the maximum read value on the voltage sensor divided by the maximum number of current bits 1024 which will produce temp currents. Then the reading current is the result of temp current divided by two, then multiplied by the constant 0.7071 , which is read and passed on the LCD so that it produces a current that is read on the current sensor one a load current monitoring tool. Then the ACS 712 current sensor is tested first. The data taken is current with a 0.5 -volt step. This data is to test how precise the current sensor is. The data from the current 
sensor test results are then tabled to find out how many errors are generated by this tool. To find out the error in Table 2.

Table 2. Current Sensor Testing

\begin{tabular}{|c|c|c|c|}
\hline $\begin{array}{c}\text { Current } \\
\text { Measure } \\
\text { (A) }\end{array}$ & $\begin{array}{c}\text { Current } \\
\text { Test } \\
\text { (A) }\end{array}$ & $\begin{array}{l}\text { Current } \\
\text { Test Con- } \\
\text { version }\end{array}$ & Error(\%) \\
\hline 0.5 & 0.5 & 102.4 & 0 \\
\hline 1 & 1 & 204.8 & 0 \\
\hline 1.5 & 1.56 & 319.4 & 4 \\
\hline 2.0 & 2.04 & 417.7 & 2 \\
\hline 2.5 & 2.51 & 514 & 0.4 \\
\hline 3.0 & 3.02 & 618.4 & 0.66 \\
\hline 3.5 & 3.55 & 727 & 1.42 \\
\hline 4.0 & 3.94 & 806.9 & 1.5 \\
\hline 4.5 & 4.45 & 911.36 & 1.11 \\
\hline 5.0 & 4.98 & 1019.9 & 0.4 \\
\hline
\end{tabular}

\section{Conclusion}

1. From the monitoring tool obtained the test results of testing Television with power 27 $\mathrm{W}$ and Voltage 19 Volt. Based on the results of voltage sensor testing, the percentage of voltage error is $1.09 \%$.

2. From the monitoring tool obtained the test results of testing Television with power 27 $\mathrm{W}$ and Voltage 19 Volt. Based on the results of current sensor testing the percentage of current error is $1.15 \%$.

3. Based on the results of the test data, it can be concluded that the current, voltage in the passenger room of the JokoTole KMP ship are fluctuating. This needs to be done monitoring the current load on the ship, especially in the safety alarm system, electronic devices, pumps for the safety of shipping, which at KMP Joko Tole still uses conventional technology and the absence of adequate electrical system data support.

\section{Acknowledgment}

This work was financially supported by Research Center for Politeknik Perkapalan Negeri Surabaya (PPNS), Mokosoft Technology, Research and Development Division.

\section{References}

1. Putra BE, Arfianto AZ, Subiyanto L, Putra ZMA, Hasin MK, Utari DA, Rahmat MB, Hidayat D, Taali M, Lusiandri AY (2019) Multi Automated Guided Vehicle (AGV) cardboard carrier using wireless communication. IOP Conf. Ser. Earth Environ. Sci. 340 (2019): 012009. doi:10.1088/1755$1315 / 340 / 1 / 012009$

2. Kumar A, Ben-Tzvi P, Saab W, Snyder MR (2016) Wireless telemetry system for real-time estimation of ship air wakes with UAVs. Mechatronics 36(2016): 18-26

3. Backes J, Bell B, Olson L (1981) Long-baseline deep ocean acoustic tracking and telemetry system. OCEANS 81: 1-8.

4. Sun S, Zhao X, Luan J, Wang C (2010) Remote control and telemetry system for large-scale model test at sea. J. Mar. Sci. Appl. 9 (3): 280-285.doi:10.1007/s11804-010-1008-3

5. Pham, C (2018) Robust CSMA for long-range LoRa transmissions with image sensing devices. Wireless Days (WD) 2018: 116-122.

6. Kumar A, Ben-Tzvi P, Snyder M (2015) UAV-based wireless telemetry system for the estimation of ship air wake patterns. ASME 2015 International Design Engineering Technical Conferences and Computers and Information in Engineering Conference.

7. Zuñiga GM (2019) Test flight using LoRa based telemetry subsystem for stratospheric balloons. Difu100ci@ Rev. en Ing. y Tecnol. UAZ 12(2): 1-10.

8. Rahmadhani A, Isswandhana R, Giovani A, Syah RA (2018) Lorawan as secondary telemetry communication system for drone delivery. IEEE International Conference on Internet of Things and Intelligence System (IOTAIS) 2018: 116-122.

9. Hassan W, Føre M, Ulvund JB, Alfredsen JA (2019) Internet of Fish: Integration of acoustic telemetry with LPWAN for efficient real-time monitoring of fish in marine farms. Comput. Electron. Agric. 163: 104850.

10. Gambi E, Montanini L, Pigini D, Ciattaglia G, Spinsante $S$ (2018) A home automation architecture based on LoRa technology and Message Queue Telemetry Transfer protocol. Int. J. Distrib. Sens. Networks 14 (10): 1550147718806837.

11. Pamungkas AD, Subiyanto L, Arfianto A. Z (2019) Rancang Bangun Telemetri Arus Beban Peralatan Elektronik Pada Ruang Penumpang Kapal Ferry Berbasis Long Range Wireless Communications (LoRA). J. Teknol. Marit. 2 (1): 23-30. 